\title{
Satisfaction of elderly patients undergoing orthopedic surgery in terms of nursing care and affecting factors
}

\author{
Figen Dığın' ${ }^{1}$, Zeynep Kızılcık Özkan ${ }^{2}$, Gürcühan Fidan ${ }^{3}$ \\ ${ }^{1}$ Department of Surgical Nursing, Faculty of Health Sciences, Kırklareli University, Kırklareli, Turkey \\ ${ }^{2}$ Department of Surgical Nursing, Faculty of Health Sciences, Trakya University, Edirne, Turkey \\ ${ }^{3}$ Oncological Surgery Clinics, Ankara City Hospital, Ankara, Turkey
}

Received: 2021-08-05.

Accepted: 2021-10-22

This work is licensed under a Creative Commons Attribution 4.0 International License

\section{J Clin Med Kaz 2021; 18(6):50-55}

\section{Corresponding author:}

Figen Dığın

E-mail: fgndgn2013@gmail.com; ORCID: 0000-0003-1861-0221

\section{Abstract}

Background: Patient satisfaction is accepted as a criterion in the evaluation of nursing care, it's important to know the factors affecting satisfaction.

Aim: The aim of this study was to determine the satisfaction of elderly patients with orthopedic surgery and factors affecting.

Material and methods: This descriptive study was conducted with 135 patients who undergoing orthopedics surgery. Data were collected using Patient identification form and Newcastle Satisfaction with Nursing Scales. Mann Whitney $U$, Kruskal Wallis $H$ tests and correlation analysis were performed.

Results: The mean score of the patients on the Newcastle Satisfaction with Nursing Scale was determined to be $83.5 \pm 15.5$. It was found that the mean score of the patients on the Newcastle Nursing Care Satisfaction Scale varied according to the companion support and socioeconomic status $(p<0.05)$

Conclusion: It was determined that elderly patients who undergoing orthopedic surgery had a good level of satisfaction with nursing care.

Key words: elderly patient, nursing care, orthopedic surgery, patient satisfaction

\section{Introduction}

The rate of elderly admitted to healthcare institutions is increasing with each passing day [1]. The elderly are admitted to healthcare institutions with chronic comorbidities, which require drug use, and with cognitive and functional disorders, which increase hospitalization risks [2]. With the functional losses and traumas in musculoskeletal system that appear because of aging, more orthopedic surgeries are performed especially in the last decade [3]. Elderly patients require longer postoperative care periods because of their physiological, psychological and emotional losses [4] and their surgical stress/anesthesia tolerances are more limited [5]. Depending on age and surgery, it is already known that the postoperative self-care requirements of elderly are semi-dependent/dependent, and the recovery process takes longer [5]. Failure in meeting the requirements in a timely manner and in providing care causes prolonged hospitalization and complications [6]. For this reason, providing quality surgical care to avoid the persistence of morbidity, improve the quality of life, and maintain the success of surgery emerges as an important requirement in this respect [5].

Nursing care and patient satisfaction remain to be an up-to-date issue [7]. Patient satisfaction is the multifactor personal evaluation regarding the healthcare service received by individuals and their expectations of these services [8,9]. Patient satisfaction is considered as the main determinant of the quality of nursing care [10]. Patient satisfaction is considered as an important criterion in evaluating the quality of healthcare and in determining the revision needs of institutions [11].

Although it is reported in the literature that patients experience dissatisfaction because of postoperative movement limitations [12] it was welcomed by patients that their self-care needs were covered by nurses [13] they were informed during treatment and care [14]. It was also recommended to shorten the length of hospital stay to increase patient satisfaction [15]. It is important 
to evaluate patient satisfaction in identifying factors that affect it, and in producing solutions to these problems [8]. Also, increasing satisfaction in nursing ensures patient agreement [16] and continuity of care [17] improving health and accelerating recovery [18].

The purpose of the study was to determine the elderly undergoing orthopedic surgery patients' satisfaction with nursing care.

\section{Materials and methods}

This study, which had a descriptive design, was conducted betweThis study, which had a descriptive design, was conducted between December 2020 and February 2021 with the participation of 135 elderly patients who undergoing scheduled major surgical intervention in orthopedics and traumatology surgery clinics of a public hospital.

Patients who were aged 65 and older undergoing orthopedic surgery constituted the universe of the study, and the minimum number of people who should be included in the sampling was calculated as 135 based on $95 \%$ confidence interval, $5 \%$ error margin, and with Newcastle Satisfaction with Nursing Scales total score average: $82.6(+/-14.8)$ [7]. Patients who were over the age of 65 , who could communicate in Turkish, who were not previously diagnosed with a psychiatric disease, who undergoing orthopedic surgery, whose discharge was planned, and who volunteered to participate in the study were included in the sampling.

Patient identification form and Newcastle Satisfaction with Nursing Scales (NSNS) were used in the study as the data collection tools.

The Patient identification form was prepared by the researchers with literature support [7,19]. There are a total of 12 questions on sociodemographic characteristics (i.e. age, gender, educational status, marital status, working status, socioeconomic level, and comorbidity) and on disease-related characteristics (i.e. surgical intervention, hospitalization type, hospitalization frequency, hospitalization time, and companion support).

The Newcastle Satisfaction with Nursing Scales (NSNS) was developed by Thomas et al. [20] in 1995 to evaluate the satisfaction regarding the nursing care in hospitals. The Turkish validity and reliability of it was conducted by Akın and Erdogan in 2007. The scale, which is in the form of 5-point likert style, consists of 19 items. After the scores of all the items of the scale are added (I am not satisfied at all=1 / I am completely satisfied $=5$ ), the score is converted into 100 , and the score evaluation is made over $0-100$ points. As the score of the scale increases, the level of satisfaction is high. The fact that the total score is 100 shows that the patient is satisfied with all aspects of nursing care. The Cronbach alpha value was found to be 0.95 in the Turkish version of the scale [21]. In the present study, Cronbach Alpha value was found to be 0.76 .

Patients who met the inclusion criteria were informed about the study; and their informed consents were received in writing. Patients were interviewed face-to-face in patient room; and the Patient identification form and NSNS were applied.

The study data were evaluated with IBM SPSS (Statistical Package for Social Sciences) version 22.0 program. Kolmogorov Smirnov test was used in determining the agreement to normal distribution, Mann Whitney U and Kruskal Wallis H tests were used in intragroup comparisons, and Spearman Correlation Analysis was used to determine the relations between the variables. Bonferroni-corrected Mann Whitney U test was used to determine the source of the difference in a group; and $p<0.05$ was considered as a statistically significant limit.
Before the study was commenced, the necessary written permissions were obtained from the Scientific Research Ethics Committee of the University (2020/06/23-P0243R00), and from the institution where the study was conducted. Patients were given verbal information about the study, and written permissions were obtained from those who volunteered to participate in the study. Patients were informed that the information they provided would only be used for study purposes, and that their privacy would be protected.

\section{Results}

It was determined that the mean age of the patients was $76.0 \pm 8.0(65-92), 64.4 \%(n=87)$ were male, and $47.4 \%(n=64)$ were elementary school graduates. It was found that $74.8 \%$ of the patients had at least one chronic disease, and 54.1\% had prosthetic surgery. The mean score of patients in NSNS was found to be $83.5 \pm 15.5(p<0.05)$. It was found that socioeconomic status and companion support affected patient satisfaction $(\mathrm{p}<0.05)$ (Table 1).

The top three items that had the highest mean score in the study were determined as the care regarding the privacy of patients, the awareness in their requirements, and being treated as individuals. The reasons for dissatisfaction were determined as the inability to feel as if at home, the contents of information about the disease and treatment, and the lack of eliminating the concerns of relatives adequately (Table 2).

It was found that socioeconomic status and companion support affected patient satisfaction $(\mathrm{p}<0.05)$. Table 3 shows the variation of patients' satisfaction on scale-item terms according to their socioeconomic status. According to results of Bonferroni corrected Mann Whitney U test; patients with a moderate socioeconomic level are more satisfied than those with a high socioeconomic level $(\mathrm{p}<0.05)$.

When the statistical effect of companion support on scale item basis is evaluated; patients with companion support were more satisfied with the helpfulness of the nurse $(p=0.006)$ and the way nurses explained things to patient $(\mathrm{p}=0.010)$ (Table 4$)$.

\section{Discussion}

It was determined in the present study that elderly surgical patients had high-level satisfaction regarding the nursing care. Abd El-Moniem, Mahfouz and Elsoued Hussein [22] found that $67.9 \%$ of hospitalized geriatric patients had moderate satisfaction levels regarding nursing care. Heyman, Osman and Natan's [23] study found that the satisfaction (treatment) of patients in geriatric rehabilitation facilities was high. The results of the study show that elderly patients are satisfied with nursing.

It was found in the study that patients who had moderate socioeconomic status were more satisfied than patients who had high socioeconomic status. In the fifteen items of the scale, it is seen that the satisfaction is significant in favor of the middle level socioeconomic level. Contradictory results are found in the literature regarding income levels. Deka et al. [24] found that satisfaction levels were higher in patients with low socioeconomic levels; however, Ozturk et al. [19] found that patients who had high socioeconomic levels were more satisfied. Also, a previous study [25] reported that patient satisfaction did not vary according to economic situation, but another study reported a linear relation between socioeconomic levels and patient satisfaction scores [26]. New studies are required to show the effectiveness of socioeconomic levels on patient satisfaction. Differences in study results may have been affected by factors such as patients' previous experiences, expectations, and characteristics. 


\begin{tabular}{|c|c|c|c|c|c|}
\hline Characteristics & & n (\%) & NSNS Mean \pm SD & Mean rank & Statistical value \\
\hline \multirow[t]{2}{*}{ Gender } & Female & $87(64.4)$ & $83.0 \pm 16.0$ & 66.82 & \multirow{2}{*}{$\begin{array}{l}p=0.629 \\
U=1985.000\end{array}$} \\
\hline & Male & $48(35.6)$ & $84.3 \pm 14.6$ & 70.15 & \\
\hline \multirow[t]{4}{*}{ Education status } & Illiterate & $45(33.3)$ & $84.5 \pm 13.0$ & 67.14 & \multirow{4}{*}{$\begin{array}{l}\mathrm{p}=0.487 \\
\mathrm{KW}=2.436\end{array}$} \\
\hline & Primary education & $64(47.4)$ & $84.8 \pm 15.7$ & 73.32 & \\
\hline & High school & $15(11.1)$ & $80.2 \pm 16.3$ & 61.03 & \\
\hline & University & $11(8.1)$ & $76.5 \pm 20.8$ & 55.86 & \\
\hline \multirow[t]{2}{*}{ Marital status } & Married & $82(60.7)$ & $83.2 \pm 16.3$ & 67.87 & \multirow{2}{*}{$\begin{array}{l}p=0.961 \\
U=2162.500\end{array}$} \\
\hline & Single & $53(39.3)$ & $84.0 \pm 14.1$ & 68.20 & \\
\hline \multirow[t]{2}{*}{ Working status } & $\begin{array}{l}\text { I cannot work due to } \\
\text { orthopedic problems }\end{array}$ & $8(5.9)$ & $88.6 \pm 12.7$ & 78.44 & \multirow{2}{*}{$\begin{array}{l}p=0.427 \\
U=424.500\end{array}$} \\
\hline & $\begin{array}{l}\text { I cannot work for other } \\
\text { reasons }\end{array}$ & $127(94.1)$ & $83.2 \pm 15.6$ & 67.34 & \\
\hline \multirow[t]{3}{*}{ Socioeconomic level } & High & $35(25.9)$ & $76.2 \pm 16.9$ & 66.20 & \multirow{3}{*}{$\begin{array}{l}\mathrm{p}=0.013 \\
\mathrm{KW}=8.679 \\
\mathrm{P}^{1}-2=0.625 \\
\mathrm{P}^{1}-3=0.402 \\
\mathrm{P}^{2}-3=0.003\end{array}$} \\
\hline & Moderate & $95(70.4)$ & $86.2 \pm 14.3$ & 74.07 & \\
\hline & Low & $5(3.7)$ & $83.3 \pm 10.6$ & 51.77 & \\
\hline \multirow[t]{2}{*}{ Comorbidity } & Yes & $101(74.8)$ & $83.9 \pm 15.1$ & 68.77 & \multirow{2}{*}{$\begin{array}{l}p=0.686 \\
U=1639.000\end{array}$} \\
\hline & No & $34(25.2)$ & $82.3 \pm 16.6$ & 65.71 & \\
\hline \multirow[t]{3}{*}{ Surgical intervention } & Prosthesis & $73(54.1)$ & $82.2 \pm 15.8$ & 64.53 & \multirow{3}{*}{$\begin{array}{l}\mathrm{p}=0.468 \\
\mathrm{KW}=1.519\end{array}$} \\
\hline & Open reduction & $48(35.6)$ & $84.5 \pm 15.5$ & 70.85 & \\
\hline & Amputation & $14(10.4)$ & $86.8 \pm 13.4$ & 76.29 & \\
\hline \multirow[t]{4}{*}{ Operation area } & Hip & $74(54.8)$ & $79.1 \pm 14.8$ & 67.42 & \multirow{4}{*}{$\begin{array}{l}\mathrm{p}=0.170 \\
\mathrm{KW}=5.025\end{array}$} \\
\hline & Knee & $27(20.0)$ & $76.0 \pm 15.6$ & 58.83 & \\
\hline & Lower extremity & $27(20.0)$ & $80.9 \pm 14.0$ & 72.09 & \\
\hline & Upper extremity & $7(5.2)$ & $88.4 \pm 8.44$ & 93.71 & \\
\hline \multirow[t]{2}{*}{ Companion support } & Yes & $130(96.3)$ & $84.1 \pm 15.2$ & 69.31 & \multirow{2}{*}{$\begin{array}{l}p=0.043 \\
U=155.000\end{array}$} \\
\hline & No & $5(3.7)$ & $69.0 \pm 15.9$ & 34.00 & \\
\hline \multirow[t]{2}{*}{ Hospitalization type } & From emergency room & $108(80)$ & $83.4 \pm 14.7$ & 67.00 & \multirow{2}{*}{$\begin{array}{l}p=0.546 \\
U=1350.500\end{array}$} \\
\hline & From policlinic & $27(20)$ & $83.9 \pm 18.6$ & 71.98 & \\
\hline \multicolumn{6}{|c|}{ Mean \pm SD } \\
\hline Ageyear & $76.0 \pm 8.0$ & & $83.5 \pm 15.5$ & & $\begin{array}{l}\mathrm{p}=0.875 \\
\mathrm{r}=0.014\end{array}$ \\
\hline $\begin{array}{l}\text { Hospitalization } \\
\text { timeday }\end{array}$ & $7.8 \pm 7.1$ & & & & $\begin{array}{l}p=0.161 \\
r=-0.121\end{array}$ \\
\hline $\begin{array}{l}\text { Hospitalization } \\
\text { frequencyday }\end{array}$ & $3.1 \pm 2.3$ & & & & $\begin{array}{l}\mathrm{p}=0.411 \\
\mathrm{r}=0.071\end{array}$ \\
\hline
\end{tabular}

NSNS: Newcastle Satisfaction with Nursing Scales N: Number of patients, SD: standard deviation, U: Mann Whitney U test, KW: Kruskal Wallis H test, r: Spearman Correlation analysis

It was also found in the study that patients who had companion support were more satisfied than patients without companion support. In their study, Kashkoli et al. [27] found that social support was a minor factor that affected patient satisfaction. Klem et al. [28] reported that the lack of familial support in elderly patients undergoing total hip arthroplasty reduced patient satisfaction. Another study reported that elderly patients without regular visitors/family support in an acute care environment had low satisfaction scores [29].

In the study, it was found that patients were highly satisfied with the care regarding their privacy (personal and bodily boundaries), awareness of their requirements, and being treated as individuals. Similarly, Zhang et al. [30] in their studies, it was determined that the highest satisfaction was respecting the privacy of patients and treating patients as individuals. These study results were supported by Dawood, GaleleAbd El Moneam and Al Anwer Ashour [31] that the care of nurses regarding privacy was highly welcomed by elderly patients. Ozsaker et al. [32] reported in their study that the care for privacy was a condition that created high satisfaction in surgical patients. Marcelina et al. [33] found that patients who undergoing radical prostatectomy were highly satisfied with their privacy. In the study conducted
Table $4 \quad$ Comparison of patient satisfaction according to subgroups of companion support $(n=135)$

\begin{tabular}{|c|c|c|c|}
\hline \multirow[t]{2}{*}{ Items } & \multicolumn{2}{|c|}{ Companion support } & \multirow{3}{*}{$\begin{array}{l}\text { Statistical } \\
\text { value }\end{array}$} \\
\hline & Yes $(n=130)$ & No $(n=5)$ & \\
\hline & Mean rank & & \\
\hline Nurses' helpfulness & 69.68 & 24.30 & $\begin{array}{l}p=0.006 \\
U=106.500\end{array}$ \\
\hline $\begin{array}{l}\text { The way nurses } \\
\text { explained things to you }\end{array}$ & 69.58 & 26.80 & $\begin{array}{l}p=0.010 \\
U=119.000\end{array}$ \\
\hline
\end{tabular}

$\mathrm{U}=$ Mann-Whitney $\mathrm{U}$ test

by Yanmis [34] it was highly welcomed that nurses were aware of the requirements of urology patients. Shankar, Bhaita and Schuur [35] reported that the lack of privacy was associated with low patient satisfaction in their study conducted with elderly emergency patients. In their systematic review in which they examined the acute care experiences of elderly patients Bridges et al. [29] found that failure in covering individual requirements caused dissatisfaction in patients. Zhang et al. [30] determine their study that patients who were hospitalized were highly satisfied with the way nurses treated patients as individuals (67.7\%). Results of study show that patients care about privacy. 


\begin{tabular}{llll}
\hline Items & & Min-Max & Mean \pm SD \\
\hline 1. & The amount of time nurses spent with you & $2-5$ & $4.18 \pm 0.8$ \\
\hline 2. & How capable nurses were at their job & $2-5$ & $4.24 \pm 0.7$ \\
\hline 3. & There always being a nurse around if you needed one & $2-5$ & $4.20 \pm 0.8$ \\
\hline 4. & The amount nurses knew about your care & $2-5$ & $4.16 \pm 0.8$ \\
\hline 5. & How quickly nurses came when you called for them & $2-5$ & $4.16 \pm 0.8$ \\
\hline 6. & The way the nurses made you feel at home & $2-5$ & $4.03 \pm 0.8$ \\
\hline 7. & The amount of information nurses gave to you about your condition and treatment & $4.10 \pm 0.8$ \\
\hline 8. & How often nurses checked to see if you were OK & $2-5$ & $4.18 \pm 0.8$ \\
\hline 9. & Nurses' helpfulness & $2-5$ & $4.24 \pm 0.8$ \\
\hline 10. & The way nurses explained things to you & $2-5$ & $4.16 \pm 0.8$ \\
\hline 11. & How nurses helped put your relatives or friends' minds at rest & $2-5$ & $4.07 \pm 0.8$ \\
\hline 12. & Nurses manner in going about their work & $2-5$ & $4.21 \pm 0.8$ \\
\hline 13. & The type of information nurses gave to you about your condition and treatment & $2-5$ & $4.07 \pm 0.8$ \\
\hline 14. & Nurses treatment of you as an individual & $2-5$ & $4.25 \pm 0.8$ \\
\hline 15. & How nurses listened to your worries and concerns & $2-5$ & $4.12 \pm 0.8$ \\
\hline 16. & The amount of freedom you were given on the ward & $2-5$ & $4.12 \pm 0.9$ \\
\hline 17. & How willing nurses were to respond to your request & $1-5$ & $4.23 \pm 0.7$ \\
\hline 18. & The amount of privacy nurses gave you & $2-5$ & $4.35 \pm 0.7$ \\
\hline 19. & Nurses awareness of your needs on your care and treatment & $2-5$ & $4.30 \pm 0.7$
\end{tabular}

\begin{tabular}{|c|c|c|c|c|}
\hline \multirow[t]{3}{*}{ Items } & \multicolumn{3}{|c|}{ Companion support } & \multirow[t]{3}{*}{ Statistical value } \\
\hline & High $(n=35)$ & Moderate ( $\mathrm{n}=95)$ & Low $(n=5)$ & \\
\hline & \multicolumn{3}{|c|}{ Mean rank } & \\
\hline There always being a nurse around if you needed one & 52.13 & 74.49 & 55.70 & $\begin{array}{l}*_{p}=0.006 \\
\mathrm{KW}=10.268\end{array}$ \\
\hline The amount nurses knew about your care & 52.11 & 73.97 & 65.80 & $\begin{array}{l}* \mathrm{p}=0.010 \\
\mathrm{KW}=9.130\end{array}$ \\
\hline How quickly nurses came when you called for them & 55.16 & 73.25 & 58.10 & $\begin{array}{l}* \mathrm{p}=0.036 \\
\mathrm{KW}=6.640\end{array}$ \\
\hline The way the nurses made you feel at home & 52.94 & 73.73 & 64.60 & $\begin{array}{l}* \mathrm{p}=0.017 \\
\mathrm{KW}=8.122\end{array}$ \\
\hline $\begin{array}{l}\text { The amount of information nurses gave to you about your } \\
\text { condition and treatment }\end{array}$ & 53.06 & 73.37 & 70.50 & $\begin{array}{l}* \mathrm{p}=0.020 \\
\mathrm{KW}=7.831\end{array}$ \\
\hline Nurses' helpfulness & 60.30 & 72.99 & 60.30 & $\begin{array}{l}* \mathrm{p}=0.045 \\
\mathrm{KW}=6.194\end{array}$ \\
\hline The way nurses explained things to you & 55.04 & 72.98 & 64.00 & $\begin{array}{l}* \mathrm{p}=0.044 \\
\mathrm{KW}=6.234\end{array}$ \\
\hline How nurses helped put your relatives or friends' minds at rest & 49.86 & 74.99 & 62.20 & $\begin{array}{l}*_{p}=0.002 \\
\mathrm{KW}=12.015\end{array}$ \\
\hline Nurses manner in going about their work & 50.84 & 74.05 & 73.10 & $\begin{array}{l}* \mathrm{p}=0.005 \\
\mathrm{KW}=10.538\end{array}$ \\
\hline $\begin{array}{l}\text { The type of information nurses gave to you about your condition } \\
\text { and treatment }\end{array}$ & 49.23 & 75.24 & 61.90 & $\begin{array}{l}* \mathrm{p}=0.002 \\
\mathrm{KW}=12.888\end{array}$ \\
\hline Nurses treatment of you as an individual & 54.74 & 73.26 & 60.80 & $\begin{array}{l}* \mathrm{p}=0.032 \\
\mathrm{KW}=6.912\end{array}$ \\
\hline How nurses listened to your worries and concerns & 49.93 & 75.07 & 60.10 & $\begin{array}{l}* \mathrm{p}=0.002 \\
\mathrm{KW}=12.242\end{array}$ \\
\hline The amount of freedom you were given on the ward & 51.14 & 74.66 & 59.40 & $\begin{array}{l}* p=0.005 \\
\text { KW }=10.781\end{array}$ \\
\hline How willing nurses were to respond to your request & 51.40 & 74.41 & 62.40 & $\begin{array}{l}* \mathrm{p}=0.005 \\
\mathrm{KW}=10.414\end{array}$ \\
\hline Nurses awareness of your needs on your care and treatment & 55.07 & 72.65 & 70.20 & $\begin{array}{l}* \mathrm{p}=0.045 \\
\mathrm{KW}=6.181\end{array}$ \\
\hline
\end{tabular}

KW = Kruskal Wallis test ${ }^{*}=$ Bonferroni corrected Mann Whitney U test show that patients with a moderate socioeconomic level are more satisfied than those with a high socioeconomic level $(p<0.05)$.

In this respect, it can be said that privacy has a significant effect on patient satisfaction.

It was determined in the present study that the most dissatisfying situation was the inability to feel as if at home, the contents of information about the disease and treatment, and the lack of adequate elimination of concerns of patient's and his/her relatives'. It was reported in previous studies that environmental variables, such as the cleanliness of the room and lack of noise for elderly hospitalized patients increased patient satisfaction [36] Silero and Zabalegui [37] reported that patients 
who were better informed about the perioperative process felt more satisfied. In the study of Gebremedhn and Lemma [38] it was found that knowledge about the disease and operation was a predictive factor in patient satisfaction. Forsberg et al. [39] reported that individualized information affected patient satisfaction positively in adult surgery patients. Emotional conditions of patients also affect postoperative satisfaction levels [40] It was also reported in one previous study that the most neglected situation of nurses during care attempts was not meeting the patient's/family's requirements for emotional support [6]. As a result, it may be speculated that the satisfaction levels of patients regarding ambient comfort, contents of the information, and psychological support to their relatives are low.

\section{Conclusion}

The findings of the study showed that elderly orthopedic patients had good satisfaction levels in terms of nursing care. It may be recommended that surgical nurses make elderly patients feel at home, individualize the contents of the information according to needs and preferences, and be more careful in addressing the concerns of the relatives of elderly patients adequately. The expectations and needs of elderly patients who do not have companion support and who have high socioeconomic levels must be determined more clearly, and patients must be supported at points where they feel low satisfaction.

\section{Strength and limitations}

Satisfaction from nursing care was evaluated with a valid and standardized scale in the present study. The study was conducted with a relatively small patient group, which affected the reliability of the results. In addition, postoperative complications were not questioned in the study. This may have affected patient satisfaction. Study findings should be interpreted with this situation in mind.

Disclosures: There is no conflict of interest for all authors.

Acknowledgements: None.

Funding: None.

\section{References}

1. Wyman MF, Shiovitz-Ezra S, Bengel J. Ageism in the health care system: providers, patients, and systems. In: Ayalon L., Tesch-Römer C. (Eds.), Contemporary perspectives on ageism. International Perspectives on Aging, 19. Cham: Springer; 2018.

2. Svanström R, Sundler AJ, Berglund M, Westin L. Suffering caused by care-elderly patients' experiences in community care. Int J Qual Stud Health Well-Being. 2013; 8(1):20603. doi: 10.3402/qhw.v8i0.20603

3. Centers for Disease Control and Prevention (CDC). (2020). Keep on your feet - preventing older adult falls. Retrieved March 14, 2021, from https://www.cdc.gov/injury/features/older-adult-falls/index.html Updated: December 16, 2020.

4. Savc1 A, Bilik O. Assessment of geriatric patients in the clinic of orthopaedic and traumatology. Dokuz Eylul University E-Journal of Nursing Faculty. 2014; 7(2):156-163.

5. Deiner S, Silverstein JH. Long-term outcomes in elderly surgical patients. Mt Sinai J Med. 2012; 79(1):95-106. doi:10.1002/msj.21288.

6. Moreno-Monsivais MG, Moreno-Rodruguez C, Interial-Guzman MG. Missed nursing care in hospitalized patients. Aquichan. 2015; 15(3):318-328. doi: 10.5294/aqui.2015.15.3.2

7. Tekin F, Yıldız Findık U. Level of perception of individualized care and satisfaction with nursing in orthopaedic surgery patients. Orthop Nurs. 2015; 34(6):371-374. doi: 10.1097/NOR.0000000000000194

8. Apay SE, Arslan S. Satisfaction level of inpatient in an university hospital. TAF Preventive Medicine Bulletin. 2009; 8(3):239-244.

9. Bourne RB, Chesworth BM, Davis AM, Mahomed NN, Charron KD. Patient satisfaction after total knee arthroplasty: who is satisfied and who is not? Clin Orthop Relat Res. 2010; 468:57-63. doi: 10.1007/s11999-009-1119-9

10. Batbaar E, Dorjdagva J, Luvsannyamm A, Savino MM, Amenta P. Determinants of patient satisfaction: a systematic review. Perspectives in Public Health. 2017; 137(2):89-101. doi: 10.1177/1757913916634136.

11. Day MS, Hutzler LH, Karia R, Vangsness K, Setia N, Bosco 3rd JA. Hospital-acquired conditions after orthopedic surgery do not affect patient satisfaction scores. J Healthc Quality. 2014; 36(6):33-40. doi: 10.1111/jhq.12031

12. Kim SJ, Bamne A, Song YD, Kang YG, Kim TK. Patients still wish for key improvements after total knee arthroplasty. Knee Surg Relat Res. 2015; 27(1):24-33. doi: 10.5792/ksrr.2015.27.1.24.

13. Kelly MP, Calkins TE, Culvern C, Kogan M, Valle CJD. Inpatient versus outpatient hip and knee arthroplasty: which has higher patient satisfaction? J Arthroplasty. 2018; 33:3402-3406. doi: 10.1016/j.arth.2018.07.025

14. Sendir M, Büyükyılmaz F, Yazgan I, Bakan N, Mutlu A, Tekin F. Evaluation of experience and satisfaction with nursing care in orthopedic and traumatology patients. Florence Nightingale J Nurs. 2012; 20(1):35-42.

15. Padilla JA, Feng J, Anoushiravani AA, Hozack WJ, Schwarzkopf R, Macaulay B. Modifying patient expectations can enhance total hip arthroplasty postoperative satisfaction. J Arthroplasty. 2019; 34(7):209-214. doi: 10.1016/j.arth.2018.12.038

16. Janet HY, Luk HKB. Patient satisfaction: Concept analysis in the healthcare context. Patient Educ Couns. 2019; 102:790-796. doi: 10.1016/j.pec.2018.11.013

17. Lautamatti E, Sumanen M, Raivio R, Mattila KJ. Continuity of care is associated with satisfaction with local health care services. $B M C$ Family Practice. 2020; 21:181. doi: 10.1186/s12875-020-01251-5

18. Azizi-Fini I, Mousavi MS, Mazroui-Sabdani A, Adib-Hajbaghery M. Correlation between nurses' caring behaviors and patients' satisfaction. Nurs Midwifery Stud. 2012; 1(1):36-40. doi: 10.5812/nms.7901

19. Ozturk H, Demirsoy N, Sayligil O. Patients' perceptions of nursing care in a university hospital. Nurs Sci Q. 2020; 33(1):12-18. doi: $10.1177 / 0894318419881798$

20. Thomas LH, McColl E, Priest J. Newcastle satisfaction with nursing scales: An instrument for quality assessment of nursing care. Quality in Health Care. 1996; 5:67-72. 
21. Akın S, Erdoğan S. The Turkish version of the Newcastle Satisfaction with Nursing Care Scale used on medical and surgical patients. $J$ Clin Nurs. 2007; 16(4):646-653.

22. Abd El-Moniem MM, Mahfouz MI, Elsoued Hussein HA. Geriatric inpatients perception of nurses' communication: the relationship between patient-centered communication practices and satisfaction with nursing care. World Journal of Nursing Sciences. 2015; 1(3):138-151. doi: 10.5829/idosi.wjns.2015.138.151

23. Heyman N, Osman I, Natan MB. Ageist attitudes among healthcare professionals and older patients in a geriatric rehabilitation facility and their association with patients' satisfaction with care. Int J Older People Nurs. 2020; 15:1-10. e12307. doi: 10.1111/opn.12307

24. Deka C, Borboruah L, Sarmah PP. Paul I. A study on patient satisfaction among the patients admitted in the in-patient departments of a tertiary health care institution in North East India. Nati J Community Med. 2020; 11(9):356-361. doi: 10.5455/njcm.20200623063100

25. Amiri M, Sadeghi E, Khosravi A. Factors influencing patient satisfaction in Shahroud Hospitals in 2018. International Journal of Health Studies. 2018; 4(1):37-41. doi: 10.22100/ijhs.v4i1.382

26. Footman K, Roberts B, Mills A, Richardson E, McKee M. Public satisfaction as a measure of health system performance: A study of nine countries in the former Soviet Union. Health Policy. 2013; 112:62-69. doi: 10.1016/j.healthpol.2013.03.004

27. Kashkoli SA, Zarei E, Daneshkohan A, Khodakarim S. Hospital responsiveness and its effect on overall patient satisfaction. Int J Health Care Qual Assur. 2017; 30(8):728-736. doi: 10.1108/IJHCQA-07-2016-0098

28. Klem NR, Smith A, O'Sullivan P, Dowsey MM, Schütze R, Kent P, et al. What influences patient satisfaction after TKA? A qualitative investigation. Clin Orthop Relat Res. 2020; 478:1850-1866. doi: 10.1097/CORR.0000000000001284

29. Bridges J, Collins P, Flatley M, Hope J, Young A. Older people's experiences in acute care settings: Systematic review and synthesis of qualitative studies. Int J Nurs Stud. 2020; 102:103469. doi: 10.1016/j.ijnurstu.2019.103469

30. Zhang J, Yang L, Wang X, Dai J, Shan W, Wang J. Inpatient satisfaction with nursing care in a backward region: a cross-sectional study from northwestern China. BMJ Open. 2020; 10:e034196. doi: 10.1136/bmjopen-2019-034196

31. Dawood SS, GaleleAbd El Moneam AA, Al Anwer Ashour HM. Nurses`caring behaviors as perceived by hospitalized geriatric patients' and its relation to their satisfaction with the quality of nursing care. IOSR Journal of Nursing and Health Science. 2020; 9(1):24-34. doi: 10.9790/1959-0901132434

32. Ozsaker E, Sevilmis H, Ozcan Y, Samast M. Nursing care perception and satisfaction levels of surgical patients. J Contemp Med. 2021; 1(2). doi: $10.16899 / \mathrm{jcm} .711131$

33. Marcelina CF, Machado Saito KA, Mirancos da Cunha ALS, Elizabeth dos Santos A. Patient's satisfaction with nursing care on the postsurgery of radical prostatectomy. Rev Rene. 2018; 19:e33961.

34. Yanmis S. Patients' satisfaction levels of nursing services at a urology unit of a university hospital. JOJ Nursing \& Health Care. 2018; 9(2):1-6. doi: 10.19080/JOJNHC.2018.09.555759

35. Shankar KN, Bhatia BK, Schuur JD. Toward patient-centered care: A systematic review of older adults' views of quality emergency care. Ann Emerg Med. 2014; 63(5):529-550. Doi: 10.1016/j.annemergmed.2013.07.509

36. Chumbler N, Otani K, Desai SP, Herrmann PA, Kurz RS. Hospitalized older adults' patient satisfaction: inpatient care experiences. SAGE Open. 2016; 1-7. doi: 10.1177/2158244016645639

37. Silero AS, Zabalegui A. Satisfaction of surgical patients with perioperative nursing care in a Spanish tertiary care hospital. SAGE Open Medicine. 2020; 6:1-9. doi: 10.1177/2050312118818304

38. Gebremedhn EG, Lemma GF. Patient satisfaction with the perioperative surgical services and associated factors at a University Referral and Teaching Hospital, 2014: a cross-sectional study. Pan Afr Med J. 2017: 27:176-190. doi: 10.11604/pamj.2017.27.176.10671

39. Forsberg A, Vikman I, Wälivaara BM, Engström Å. Patients' perceptions of quality of care during the perioperative procedure. $J$ Perianesth Nurs. 2015; 30(4):280-289.

40. Bae JY, Kim JK, Yoon J, Kim JH, Ho BC. Preoperative predictors of patient satisfaction after carpal tunnel release. Orthop Traumatol Surg Res. 2018; 104:907-909. doi: 10.1016/j.otsr.2018.04.004 